\title{
Pendekatan Reciprocal Teaching Berbantuan Wondershare Quiz Creator Pada Pembelajaran Matematika
}

\author{
Lala Anggraini ${ }^{1}$, Achmad Hidayatullah ${ }^{2}$, Endang Suprapti ${ }^{3}$ \\ 1,2,3 Pendidikan Matematika, Universitas Muhammadiyah Surabaya, Surabaya \\ *lalaanggraini995@gmail.com
}

\begin{abstract}
Abstrak
Penelitian ini menjelaskan dan mengelaborasi pengaruh pembelajaran Reciprocal Teaching dengan media Wondershare Quiz Creator terhadap hasil belajar matematika pada kelas VIII-B SMP Muhammadiyah 13 Surabaya. Penelitian ini dilakukan untuk meningkatkan hasil belajar matematika peserta didik. Penelitian menggunakan metode True Experiment dengan model Pretest-Posttest Control Group Design. Data tes dikumpulkan melalui pretest dan posttest, dan lembar observasi aktivitas siswa dan guru, serta angket respon peserta didik dianalisis secara deskriptif kuantitatif. Hasilnya (1) Berdasarkan uji t didapatkan rata-rata skor tes akhir pada kelas eksperimen lebih baik dari pada kelas kontrol; (2) Aktivitas peserta didik paling dominan terjadi adalah aktivitas berpartisipasi dalam menyelesaikan masalah dengan berdiskusi bersama kelompok dengan persentase sebesar 37\%; (3) Aktivitas guru mendapat skor rata-rata 3,72 yang berarti sangat baik; dan (4) Respon siswa terhadap pembelajaran positif dengan skor 95,6\%. Sehingga, dapat disimpulkan bahwa pembelajaran reciprocal teaching berbantuan wondershare quiz creator berpengaruh positif dan signifikan.
\end{abstract}

Kata kunci: Matematika; Reciprocal Teaching; Wondershare Quiz Creator

\begin{abstract}
This research describes and elaborates on the effect of Reciprocal Teaching assisted Wondershare Quiz Creator media to Mathematics learning outcome in the VIII.B class students of SMP Muhammadiyah 13 Surabaya. This research was conducted to enhance students' mathematics outcomes by using True Experimental research design with PretestPost-test Control Group Design. The collecting data technique used to pretest and posttest also students' and teachers' activity observation worksheet and students' response questionnaire; all the instruments were analyzed using descriptive quantitative. The results show (1) based on t-test measurement, it is found that the average of the final score of the experimental group is better than the control group; (2) the most dominant on students' activity is participating in problem-solving activities by discussing with groups with the result of $37 \%$; (3) teachers activities score an average of 3.72 which means very good; (4) students indicate positive respond on learning with a score of $95.6 \%$. So, it can be concluded that the reciprocal teaching approach assisted the wonder-share quiz creator which has a positive and significant effect.
\end{abstract}

Keywords: Mathematics; Reciprocal Teaching; Wonder-Share Quiz Creator

\section{PENDAHULUAN}

Matematika merupakan salah satu pelajaran yang selalu diterima oleh peserta didik mulai tingkat dasar hingga perguruan tinggi. Proses transformasi matematika oleh guru selama ini merupakan pembelajaran yang terstruktur sebagai berikut: (1) elaborasi pada objek matematika, (2) menyediakan contoh objek matematika yang telah dijelaskan, (3) meminta peserta didik untuk menyelesaikan soal, dan (4) pemberian latihan soal (Holisin, 2007). Pendekatan pembelajaran ini, berimplikasi terhadap kebosanan, tidak menarik, dan hasil 
belajar matematika belum memuaskan (Holisin, 2007). Banyak guru yang merasa kesulitan mengaktifkan peserta didik sehingga pembelajaran belum memenuhi standar sesuai yang diharapkan (Surayya, Subagia, \& Tika, 2014). Saat ini, pendidikan harus direncanakan dengan baik agar pembelajaran dapat mengembangkan potensi diri peserta didik dan suasana belajar peserta didik secara aktif. Pembelajaran yang semula berpusat pada guru harus diubah menjadi berpusat pada siswa (Soemantri, 2019).

Menurut Fannani (2014), menjelaskan bahwa memerlukan kearifan dalam pertimbangan pemilihan pendekatan pembelajaran dengan mengkonsentrasikan peserta didik agar tujuan menjadi maksimal. Untuk menaikkan output dan partisipasi aktif anak, dapat digunakan berbagai jenis pendekatan pembelajaran dalam proses pembelajaran. Reciprocal Teaching merupakan salah satu pendekatan dalam pembelajaran yang dapat dipakai pada proses transformasi matematika di kelas. Menurut Rachmawati (2014), empat strategi pemahaman yang perlu diterapkan dalam Reciprocal Teaching yakni: membuat kesimpulan pokok bahasan, menyusun berbagai pertanyaan kemudian menyelesaikannya, elaborasi informasi yang didapat, dan menaksir masalah berikutnya dari persoalan yang disampaikan kepada peserta didik. Dalam proses pembelajaran keempat strategi tersebut harus diterapkan seluruhnya sehingga mampu memperbaiki keaktifan peserta didik. Pada pendekatan ini, cara guru menyampaikan bahan ajar dapat diadaptasi oleh peserta didik, serta diterapkannya gaya belajar melalui kegiatan mengajarkan teman (Nurhayati, 2014).

Awaliah \& Idris (2015), menyatakan bahwa reciprocal teaching dapat menciptakan interaksi positif antar peserta didik melalui cara mengkomunikasikan gagasan atau temuan peserta didik kepada peserta didik lainnya, dengan demikian konsep dapat dipahami dan dikuasai. Pratiwi \& Widayati (2012) mendeskripsikan keunggulan pendekatan ini yaitu (1) Mampu melatih dan meningkatkan kemampuan anak belajar sendiri, (2) Mampu melatih individu untuk dapat menjelaskan kembali penemuan kepada yang lain, (3) Pendekatan ini memungkinkan peserta didik dalam menjelaskan temuannya, (4) Investigasi dan penemuan merupakan orientasi dalam pembelajaran, (5) Mereka menjadi lebih gampang dalam mengingat konsep karena mereka melakukan penemuan dan penyelidikan, (6) Memberi peluang untuk self learning. Selain meningkatkan keaktifan, pembelajaran reciprocal teaching dapat meningkatkan kreativitas siswa dalam menemukan ide baru untuk memecahkan masalah. Hal tersebut sejalan dengan hasil penelitian yang dilakukan oleh Tatag Bagus Argikas dan Nanang Khuzaini pada tahun 2016 dengan judul "Penerapan Pembelajaran Reciprocal Teaching Untuk Meningkatkan Pemahaman Konsep Matematika Peserta didik Kelas VII SMP Negeri 2 Depok", menunjukkan bahwa dengan penerapan 
pembelajaran reciprocal teaching dapat meningkatkan pemahaman konsep matematika peserta didik.

Namun belum ada penelitian sebelumnya yang menerapkan pembelajaran reciprocal teaching dipadukan dengan media pembelajaran, sehingga pembelajaran mudah dicerna oleh mereka dan lebih bermakna. Menurut Mudlofir dan Rusydiyah dalam Utami, Kurnia, Octafiana, \& Mursyidah (2018) media pembelajaran memegang peranan penting dan salah satu komponen penunjang dalam kelangsungan proses pembelajaran baik formal maupun non formal untuk dapat menumbuhkan sikap belajar pada peserta didik sehingga tercipta partisipasi aktif peserta didik dalam kelas. Salah satu media pembelajaran yang fleksibel dan sangat mudah digunakan yaitu media pembelajaran berbantuan komputer. Khoiri, Sa'adah, \& Saefan, (2017) menerangkan bahwa media pembelajaran berbantuan komputer dapat memberi tampilan masalah kehidupan sehari-hari dan disertai dengan video pemaparan masalah sehingga seseorang dapat melakukan observasi secara tidak langsung.

Media berbantuan komputer yang digunakan dalam penelitian ini adalah wondershare quiz creator dengan kelebihan yaitu media pembelajaran berlatar masalah. Wondershare quiz creator memungkinkan pembuatan program evaluasi pembelajaran berbasis IT(Meryansumayeka, Virgiawan, \& Marlini, 2018). Media ini merupakan media quiz dapat dipakai oleh guru dalam memberikan bahan ataupun latihan evaluasi. Media tersebut diterapkan guna memberikan motivasi peserta didik untuk mengingat kembali materi sebelumnya (Nugroho, 2015). Dengan begitu dapat memberikan perubahan pada hasil belajar untuk aspek kognitif dan afektif peserta didik.

Hasil belajar menunjukkan tentang apa yang dapat dilakukan oleh siswa sebagai output dari kegiatan belajar. Hasil belajar mereka dapat meningkat dengan menggunakan media berbantuan wondershare quiz creator karena suasana dalam pelaksanaan evaluasi pembelajaran dapat menjadi nyaman, sehingga dapat membangkitkan convidence anak dalam mengerjakan soal (Dafitri, 2017). Oleh karena itu diperlukan penelitian untuk melihat pengaruh pendekatan reciprocal teaching berbantuan wondershare quiz creator terhadap output kognitif matematika.

Berdasarkan pemaparan permasalahan tersebut, maka dalam penelitian ini akan dibahas mengenai: (1) apakah ada pengaruh penerapan reciprocal teaching berbantuan wondershare quiz creator terhadap pembelajaran matematika, dan (2) bagaimana respon peserta didik terhadap pembelajaran reciprocal teaching berbantuan wondershare quiz creator. 


\section{METODE}

Jenis penelitian yang digunakan yaitu penelitian eksperimen. Penelitian menggunakan bentuk metode true experimental design dengan desain penelitian pretest-postest control grup design. Penelitian untuk mengetahui pengaruh penerapan pembelajaran reciprocal teaching berbantuan wondershare quiz creator dan mengetahui respon peserta didik terhadap pembelajaran ini. Penelitian jenis ini menjelaskan perbedaan dari hasil pre-test dan post-test pada kelas eksperimen dan kontrol (Sugiyono, 2014). Dari hasil pre-test dan post-test dapat menunjukkan ada atau tidaknya pengaruh pembelajaran reciprocal teaching berbantuan wondershare quiz creator.

Data dikumpulkan melalui mekanisme tes, lembar observasi aktivitas objek dan guru saat proses pembelajaran, serta angket respon balik objek penelitian. Teknik analisis penelitian adalah (1) validitas instrumen (2) reliabilitas instrumen, (3) uji normalitas, (4) uji homogenitas, (5) uji perbedaan dua rata-rata/uji t, (6) ketuntasan pembelajaran, (7) aktivitas siswa, (8) Aktivitas pengajar pada pembelajaran, (9) angket respon peserta didik.

Instrumen tes dipilih untuk mengetahui hasil awal dan hasil akhir dari suatu tindakan. Instrumen tes di ujicoba terlebih dahulu di SMP Muhammadiyah 2 Surabaya untuk mengetahui apakah instrumen tes valid dan layak digunakan. Penelitian dilaksanakan di SMP Muhammadiyah 13 Surabaya pada kelas VIII-A dan VIII-B. Untuk memastikan sampel berdistribusi normal melalui uji normalitas. Kemudian untuk menghitung kesamaan varian yang normal, digunakan uji homogenitas. Dan untuk melihat pengaruh pendekatan reciprocal teaching berbantuan wondershare quiz creator menggunakan uji independent sampel t-test.

Indikator instrumen tes yang digunakan adalah diberikan berbagai permasalahan mengenai materi teorema Pythagoras yang berkaitan dengan kehidupan sehari-hari, salah satunya yaitu seorang anak yang akan mengambil layang-layang yang tersangkut di atas tembok. Peserta didik diharapkan dapat menentukan panjang tangga minimal yang diperlukan agar ujung tangga bertemu dengan bagian atas tembok.

Respon siswa merupakan reaksi dan perilaku peserta didik selama pembelajaran (Khairiyah, 2019). Angket respon terhadap pembelajaran reciprocal teaching berbantuan wondershare quiz creator terdiri dari 10 pernyataan dengan pilihan jawaban yaitu sangat setuju, setuju, tidak setuju, sangat tidak setuju. Pernyataan dimaksudkan agar dapat mengetahui ketertarikan mereka selama proses penelitian pembelajaran 


\section{HASIL PENELITIAN}

Dalam proses pembelajaran, media wondershare quiz creator digunakan di akhir pembelajaran dengan bantuan laptop milik sekolah dan peserta didik. Dalam pembelajaran menggunakan media wondershare quiz creator, peserta didik antusias selama proses pembelajaran. Hal tersebut ditunjukkan pada gambar.1

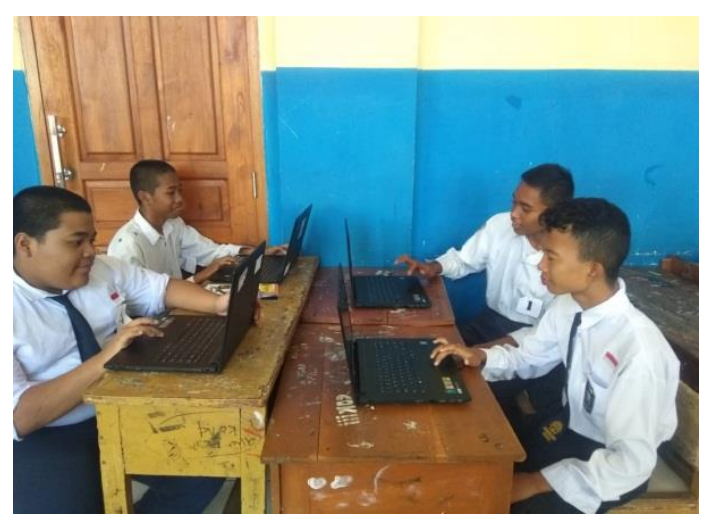

Gambar 1. Peserta Didik Sedang Menggunakan Media Wondershare Quiz Creator

Hasil penelitian ini dikelompokkan menjadi 7, yaitu hasil validitas dan reliabilitas intrumen uji coba, hasil posttest, ketuntasan hasil belajar, aktivitas peserta didik dan guru dalam pembelajaran, serta angket respon peserta didik. Uji validitas melalui corelasi product moment (Arikunto, 2014). Berdasarkan uji validitas data uji coba, instrumen tes memiliki nilai $r_{\text {hitung }}>r_{\text {tabel }}$ dan dapat disimpulkan bahwa seluruh instrumen tes valid.

Setelah itu, pengujian reliabilitas data uji coba instrumen pretest dan posttest. Hasilnya didapatkan angka 0,867. Maka hasil pengujian reliabilitas instrumen adalah reliabel dan dinyatakan layak dipakai. Pengujian data dalam penelitian ini menggunakan rumus Kolmogorov-smirnov. Posttest diikuti oleh kelas eksperimen dengan jumlah peserta didik sebanyak 22 orang dan kelas kontrol sebanyak 22 orang.

Tabel 1. Uji Normalitas Posttest Kelas Eksperimen dan Kelas Kontrol

\begin{tabular}{|c|c|c|c|}
\hline & & Control Class & Experiment Class \\
\hline $\mathrm{N}$ & & 22 & 22 \\
\hline Normal & Nilai tengah & 70.23 & 82.59 \\
\hline Parameters $^{\mathrm{a}}$ & $\begin{array}{l}\text { Std. } \\
\text { Deviation }\end{array}$ & 9.566 & 12.172 \\
\hline Most Extreme & Absolute & .146 & .143 \\
\hline Differences & Positive & .105 & .090 \\
\hline & Negative & -.146 & -.143 \\
\hline Kol.-Smir. Z & & .683 & .671 \\
\hline Asymptot. Sig. & ailed) & .739 & .759 \\
\hline
\end{tabular}

Test distribution is Normal. 
Berdasarkan tabel Kolmogrov-Smirnov ini nilai $K S_{\text {tabel }}$ adalah 0,281 dengan jumlah sampel 22 dan signifikansi 0,05. Pada Tabel 1 di atas, untuk kelas eksperimen $K S_{\text {hitung }}=$ $0,143 \leq K S_{\text {tabel }}=0,281$ dan pada kelas kontrol $K S_{\text {hitung }}=0,146 \leq K S_{\text {tabel }}=0,281$, sehingga $H_{0}$ diterima dan data berdistribusi normal.

Setelah sampel data posttest kelas eksperimen dan kontrol telah dinyatakan berdistribusi normal, Uji homogeniitas varian data dapat dillakukan. Levene statistic uji homogenitas menunjukkan 0,477, p-value (Sig). yaitu 0,493. Karena nilai signifikansi 0,493> 0,05 maka tidak terdapat perbedaan hasil belajar antara kedua kelas (Homogen).

Untuk mengukur perbedaan rata-rata skor tes akhir antara kelas eksperimen dan kontrol adalah dengan menggunakan uji t. Uji t yang digunakan yaitu independent sample t-test. Hasil pengujian ditampilkan pada tabel 2.

Tabel 2. Uji Perbedaan Rata-Rata Posttest Kelompok Eksperimen dan Kontrol

\begin{tabular}{|c|c|c|c|c|c|c|c|c|}
\hline & & & & & $\begin{array}{l}\text { Sig. } \\
(2-\end{array}$ & $\begin{array}{c}\text { Mean } \\
\text { Differenc }\end{array}$ & $\begin{array}{c}\text { Std. } \\
\text { Error } \\
\text { Differenc }\end{array}$ & $\begin{array}{c}95 \% \\
\text { Confidence } \\
\text { Interrval of } \\
\text { the } \\
\text { Difference' }\end{array}$ \\
\hline & $\mathrm{F}$ & Sig. & $\mathrm{t}$ & Df & tailed) & $\mathrm{e}$ & $\mathrm{e}$ & Lower Upper \\
\hline $\begin{array}{l}\text { Hasil Equal } \\
\text { Post V.A. }\end{array}$ & .477 & .493 & $\begin{array}{r}3.74 \\
6\end{array}$ & 42 & .001 & 12.364 & 3.301 & $\begin{array}{rr} & 19.02 \\
\end{array}$ \\
\hline $\begin{array}{ll}\text { test Equal } \\
& \text { V.n.A }\end{array}$ & & & $\begin{array}{r}3.74 \\
6\end{array}$ & $\begin{array}{r}39.77 \\
8\end{array}$ & .001 & 12.364 & 3.301 & $\begin{array}{rr}5.692 & 19.03\end{array}$ \\
\hline
\end{tabular}

Dengan ini nilai $t_{\text {tabel }}$ dengan sig 0,05 serta $d f=42$ adalah 2,018. Karena $t_{\text {hitung }}=$ $3,746>t_{\text {tabel }}=2,018$, maka $H_{0}$ ditolak. Berdasarkan hasil independent sample t test di atas, maka terdapat perbedaan rata-rata skor posttest antara kelas eksperimen dan kontrol.

Pengelolaan data ketuntasan hasil belajar peserta didik dilakukan dengan presentase ketercapaian klasikal (Sudjana dalam Hikmah, 2016):

Persentase Ketercapaian Klasikal $=\frac{\text { banyak peserta didik yang tuntas }}{\text { banyak peserta didik seluruhnya }} \times 100 \%$

$$
\begin{aligned}
& =\frac{17 \text { peserta didik }}{22 \text { peserta didik }} \times 100 \% \\
& =77,3 \%
\end{aligned}
$$

Berdasarkan perhitungan di atas terlihat bahwa nilai tuntas sebanyak 17 anak dengan total keseluruhan 22 orang, maka didapatkan nilai persentase klasikal ketuntasan hasil belajar sebesar 77,3\%. Karena persentase ketercapaian klasikal $\geq 70 \%$ dengan demikian dikatakan bahwa hasil belajar tuntas. 
Data aktivitas siswa yang diperoleh dari hasil penelitian akan dianalisis dengan cara menghitung besar persentase penilaian untuk partisipasi di kelas. Pengamatan dilakukan 2 kali dalam 2 kegiatan pembelajaran. Menurut Tazminar (2015) salah satu jenis indikator aktivitas belajar peserta didik adalah mental activities yaitu dengan menanggapi, mengingat, menganalisis, dan menyelesaikan masalah. Berdasarkan analisis data, aktivitas yang dominan dilakukan peserta didik adalah aktivitas "berpartisipasi dalam menyelesaikan masalah dengan berdiskusi bersama kelompok" dengan rata-rata 37\% dan aktivitas yang paling minim dilakukan peserta didik adalah aktivitas "menyatakan hasil diskusi melalui presentasi di kelas" dengan rata-rata $11 \%$.

Analisis aktivitas guru dilakukan dengan menghitung rata-rata skor setiap aktivitas pengajar selama proses pembelajaran. Berikut merupakan hasil analisis rata-rata skor aktivitas pengajar pada kelas eksperimen.

Tabel 3. Hasil Rata-Rata Aktivitas Guru Pada Pembelajaran

\begin{tabular}{cccc}
\hline \multirow{2}{*}{ Aktivitas } & \multicolumn{2}{c}{ Pertemuan Ke- } & \multirow{2}{*}{ Rata-Rata } \\
\cline { 2 - 3 } & $\mathbf{1}$ & $\mathbf{2}$ & 3,65 \\
Pendahuluan & 3,7 & 3,6 & 3,575 \\
Inti & 3,55 & 3,6 & 3,75 \\
Penutup & 3,5 & 3,75 & 3,625 \\
Pengelolaan Waktu & 3,5 & 3,5 & 4 \\
Suasana Kelas & 4 & 4 & $\mathbf{3 , 7 2}$ \\
\hline \multicolumn{2}{c}{ Total Rata-Rata }
\end{tabular}

Peran guru menurut Kirom (2017), yaitu (1) mampu memberi impuls kepada siswa, (2) berinteraksi dengan baik, (3) menjelaskan manfaat dari mempelajari suatu materi, dan (4) pemberi informasi, fasilitator, dan seorang model bagi peserta didik telah tercapai secara keseluruhan. Hal ini dibuktikan dengan rata-rata skor perilaku pengajar saat menerapkan pendekatan reciprocal teaching berbantuan wondershare quiz creator mendapatkan 3,72, artinya sangat baik.

Respon peserta didik terhadap pembelajaran reciprocal teaching berbantuan wondershare quiz creator adalah positif karena banyaknya peserta didik menjawab semua pernyataan dengan pilihan jawaban setuju \& sangat setuju. Karena jumlah persentase jawaban sangat setuju dan setuju adalah 95,6\%, maka respon sangat positif. 


\section{PEMBAHASAN}

Hasil penelitian menunjukkan adanya pengaruh pendekatan reciprocal teaching berbantuan wondershare quiz creator terhadap hasil belajar siswa. Diperoleh hasil yang signifikan pada aktivitas dan hasil kognitif anak sehingga pembelajaran dengan menerapkan pendekatan reciprocal teaching mampu memperbaiki kualitas belajar kelas VIII SMP Muhammadiyah 13 Surabaya. Melalui penggunaan pendekatan reciprocal teaching berbantuan wondershare quiz creator tidak hanya mampu meningkatkan output kognitif, namun berimplikasi terhadap mutu atau partisipasi siswa dalam bentuk tindakan di dalam pembelajaran. Selanjutnya aplikasi teknologi pembelajaran wondershare quiz creator berdampak terhadap hasil belajar peserta didik karena suasana dalam pelaksanaan evaluasi pembelajaran dapat menjadi sportif dan tenang, sehingga dapat membangkitkan rasa percaya diri peserta didik dalam mengerjakan soal (Dafitri, 2017).

Dalam pendekatan pembelajaran ini, sikap sosial peserta didik dapat meningkat. Hal ini karena cara guru menyampaikan bahan ajar dapat diadaptasi oleh peserta didik, serta diterapkannya gaya belajar melalui kegiatan mengajarkan teman. Penelitian lain menyatakan bahwa terdapat peningkatan kemampuan komunikasi matematis peserta didik yang belajar menggunakan pendekatan reciprocal teaching lebih baik dari pembelajaran secara konvensional (Nurhayati, 2014).

Pendekatan reciprocal teaching juga dapat menciptakan interaksi positif antar peserta didik melalui cara mengkomunikasikan gagasan atau temuan peserta didik kepada peserta didik lainnya, dengan begitu topik tertentu dapat dikuasi dan tercapai dengan baik (Awaliah \& Idris, 2015). Hasil uji $t$ menunjukkan bahwa terdapat perbedaan lebih baik setelah peserta didik mendapat treatment penerapan pembelajaran reciprocal teaching berbantuan wondershare quiz creator. Hal ini menerangkan bahwa adanya pengaruh penerapan reciprocal teaching berbantuan wondershare quiz creator pada pembelajaran matematika. Pendekatan reciprocal teaching membantu anak agar lebih mudah dalam mengingat suatu konsep karena mereka menemukan dan menyelidiki konsep yang sedang dibahas secara mandiri serta memberi peluang untuk memantau pemahaman sendiri (Pratiwi \& Widayati, 2012).

Respon peserta didik sangat baik dengan adanya pembelajaran reciprocal teaching berbantuan wondershare quiz creator. Peserta didik mampu memberikan reaksi positif pada guru dengan menaikkan hasil dan kualitas partisipasi aktif anak selama proses pembelajaran. 


\section{SIMPULAN}

Berdasarkan analisis dan pembahasan hasil dapat disimpulkan bahwa, (1) ada pengaruh penerapan pendekatan reciprocal teaching berbantuan wondershare quiz creator terhadap output belajar matematika anak kelas VIII SMP Muhammadiyah 13 Surabaya, dan (2) diperoleh hasil analisis respon peserta didik dengan jumlah persentase jawaban "sangat setuju" dan "setuju" untuk semua pernyataan sebesar 95,6\%. Oleh karena itu respon peserta didik terhadap pembelajaran matematika dengan penerapan pembelajaran reciprocal teaching berbantuan wondershare sangat positif.

\section{REFERENSI}

Arikunto, S. (2014). Dasar-Dasar Evaluasi Pendidikan. Jakarta: Rineka Cipta.

Awaliah, R., \& Idris, R. (2015). Pengaruh Penggunaan Model Reciprrocal Teaching Terhadap Hasil Belajar Matematka Peserta didik Kelas VII MTSN Balang-Balang Kecamatan Bontomarannu Kabupaten Gowa. MaPan: Jurnal Matematika Dan Pembelajaran, 3(1), 59-72. Doi : https://doi.org/10.24252/mapan.2015v3n1a6

Dafitri, H. (2017). Pemanfaatan Wondershare Quiz Creator Dalam Tes Berbasis Komputer. Jurnal Sistem Informasi, 1(1), 8-18.

Fannani, Z. (2014). Tafsir Surat An-Nahl Ayat 125 (Kajian Tentang Metode Pembelajaran). Jakarta.

Hikmah, N. (2016). Peningkatan Hasil Belajar Matematika Tentang Penjumlahan dan Pengurangan Bilangan Bulat Melalui Alat Peraga Mistar Bilangan Pada Siswa Kelas IV SDN 005 Samarinda ULU. Pendas Mahakam: Jurnal Pendidikan Dasar, 1(1), 80-85

Holisin, I. (2007). Pembelajaran Matematika Realistik (PMR). Didaktis, 5(3), 1-68. Doi: http://dx.doi.org/10.30651/didaktis.v7i3.255

Khairiyah, U. (2019). Respon Siswa Trhadap Media Dakon Matematika Materi KPK dan FPB pada Siwa Kelas IV SD/MI Lamongan. AL-MURABBI: Jurnal Studi Kependidikan dan Keislaman, 5(2), 197-204.

Khoiri, N., Sa'adah, N. I., \& Saefan, J. (2017). Mengajarkan Kemampuan Berpikir Tingkat Tinggi dengan Model Problem Based Learning Berbantuan Wondershare Quiz Creator. Jurnal Penelitian Pembelajaran Fisika, 8(2), 109-114. Doi: http://dx.doi.org/10.26877/jp2f.v8i2.1628

Kirom, A. (2017). Peran Guru dan Peserta Didik Dalam Proses Pembelajaran Berbasis Multikultural. Al-Murabbi: Jurnal Pendidikan Agama Islam, 3(1), 69-80. 
Meryansumayeka, Virgiawan, M., \& Marlini, S. (2018). Pengembangan Kuis Interaktif Berbasis E-Learning Degan Menggunakan Aplikasi Wodershare Quiz Creator pada Mata Kuliah Belajar dan Pembelajaran Matematika. Journal Pendidikan Matematika, 12(1), 29-42. Doi: https://doi.org/10.22342/jpm.12.1.5094.29-42

Nugroho, S. A. (2015). Peningkatan Keaktifan dan Hasil Belajar Peserta didik Melalui Penerapan Teori Belajar Kontruktivisme Dengan Memanfaatkan Media Pembelajaran Wondershare Quiz Creator Pada Mata Pelajaran Matematika Peserta didik Kelas II SD Negeri 2 Pacarmulyo [Universitas Negeri Semarang]. lib.unnes.ac.id/20493/

Nurhayati, N. (2014). Pengaruh Pembelajaran Dengan Pendekatan Reciprocal Teaching Terhadap Peningkatan Kemampuan Komunikasi dan Disposisi Matematis Peserta didik SMP. [Universitas Pendidikan Indonesia]. http://repository.upi.edu/11778/

Pratiwi, I., \& Widayati, A. (2012). Pembelajaran Akutansi Melalui Reciprocal Teaching Model Untuk Meningkatkan Penguasaan Konsep dan Kemandirian Belajar Dalam Materi Mengelola Administrasi Surat Berharga Jangka Pendek Peserta didik Kelas X Akutansi 1 SMK Negeri 7 Yogyakarta Tahun Pelajaran 2011/201. Jural Pendidikan Akuntansi Indonesia, 10(2), 133-152. Doi: https://doi.org/10.21831/jpai.v10i2.917

Rachmawati, D. (2014). Penerapan Pembelajaran Reciprocal Teaching Untuk Meningkatkan Kemampuan Komunikasi Matematis dan Kemandirian Belajar Matematika Peserta didik. Jurnal Pendidikan Unsika, 2(1), 13-23.

Soemantri, S. (2019). PBL Dengan Pendekatan Realistic Mathematic Meningkatkan Karakter Siswa Berkebutuhan Khusus. Math Didactic: Jurnal Pendidikan Matematika, 5(1), 112. Doi: https://doi.org/10.33654/math.v5i1.468

Sugiyono. (2014). Metode Penelitian Kuantitatif, Kualitatif, dan R\&D. Bandung: Alfabeta.

Surayya, L., Subagia, I. W., \& Tika, I. N. (2014). Pengaruh Model Pembelajaran Think Pair Share Terhadap Hasil Belajar IPA Ditinjau dari Keterampilan Berpikir Kritis Peserta didik. E-Jurnal Program Pascasarjana Universitas Pendidikan Ganesha, 4(1), 1-11.

Tazminar. (2015). Meningkatkan Keaktifan Belajar Dan Hasil Belajar Peserta didik Dengan Menggunakan Model Pembelajaran Examples non Examples. JUPENDAS, 2(1), 45-57.

Utami, N., Kurnia, I., Octafiana, L., \& Mursyidah, H. (2018). Engklek Geometri: Upaya Pelestarian Permainan Tradisional Melalui Proses Pembelajaran Matematika Di SMP Muhammadiyah 4 Surabaya. J-ADIMAS (Jurnal Pengabdian Kepada Masyarakat), 6(1), 12-18. Doi: http://dx.doi.org/10.29100/j-adimas.v6i1.678 